\title{
On the origin: environmental biology of fishes
}

\author{
Ian C. Potter
}

Received: 24 November 2009 / Accepted: 13 January 2010/Published online: 17 February 2010

(C) Springer Science+Business Media B.V. 2010

David Noakes has provided me with the daunting task of delving into my increasingly unreliable memory to recall my involvement in the events that led to the genesis of our journal, Environmental Biology of Fishes. During the 1970s, I was fortunate to have been an annual visitor to the Zoology Department at the University of Guelph, Ontario, Canada, where I spent a considerable amount of enjoyable time working with my good friend Bill Beamish on various features of the biology of lampreys (e.g., Beamish and Potter 1975). Bill was a senior Professor and Chair in the Department and had a very active research group that studied lampreys and teleost fishes. We frequently noted the shortage of journals that focused on publishing articles that explored the ways in which various aspects of different species or taxonomic groups of fishes could be related to the characteristics of the particular environment in which they lived.

As Bill Beamish recently reminded me, the early 1970s was a period when universities in Canada were undergoing such a rapid expansion and development that many academic research workers and administrators were not sure precisely how to respond to these extreme changes. As part of the rapid expansion in the

I. C. Potter $(\bowtie)$

Centre for Fish and Fisheries Research,

School of Biological Sciences and Biotechnology,

Murdoch University,

South St,

Murdoch 6150 Western Australia, Australia

e-mail: i.potter@murdoch.edu.au early 1970s, Eugene Balon came to the Zoology Department at the University of Guelph. Eugene recognized that the time was ripe to break away from the relatively broad form of scientific communication to one that was more specialized and directed. In particular, he recognized that there was a great opportunity to develop a new journal that focused on the biology of fishes, an area in which the University of Guelph, and Canada in general, were world leaders.

Eugene approached the publishing house of Dr W. Junk to ascertain whether it was interested in supporting a new journal that would be based solely on fishes. Fortunately that publishing house felt that this was an excellent idea. He then solicited ideas from a number of biologists regarding the possible content, structure and format of the journal. Knowing that Bill Beamish and I were keen that fish biologists should have access to a journal that provided a forum for publishing papers that related any aspect of the biology of fishes to the environment (e.g. Beamish 1979; Potter et al. 1979), Eugene asked us to suggest an appropriate title. I remember relaxing with Bill, after one of our regular games of squash, and for us coming up with the title Environmental Biology of Fishes. Eugene and Dr W. Junk accepted the title and this led to the selection of members of an Editorial Board that were particularly sympathetic to the aims of the new journal. I am delighted to have been associated for so many years with a journal that continues to fulfil such an important need for numerous fish biologists throughout the world.

I have continued to study lampreys and environmental aspects of the biology of fishes in Australia 
Fig. 1 Ian Potter, still actively involved in lamprey research, is seen here with some of his current and past $\mathrm{PhD}$ students at Murdoch University in Perth, Western Australia (left to right: Ben French, Ian Potter, Peter Coulson, Thea Linke, Fiona Valesini and Ashlee Jones; photograph courtesy of Ian C. Potter)

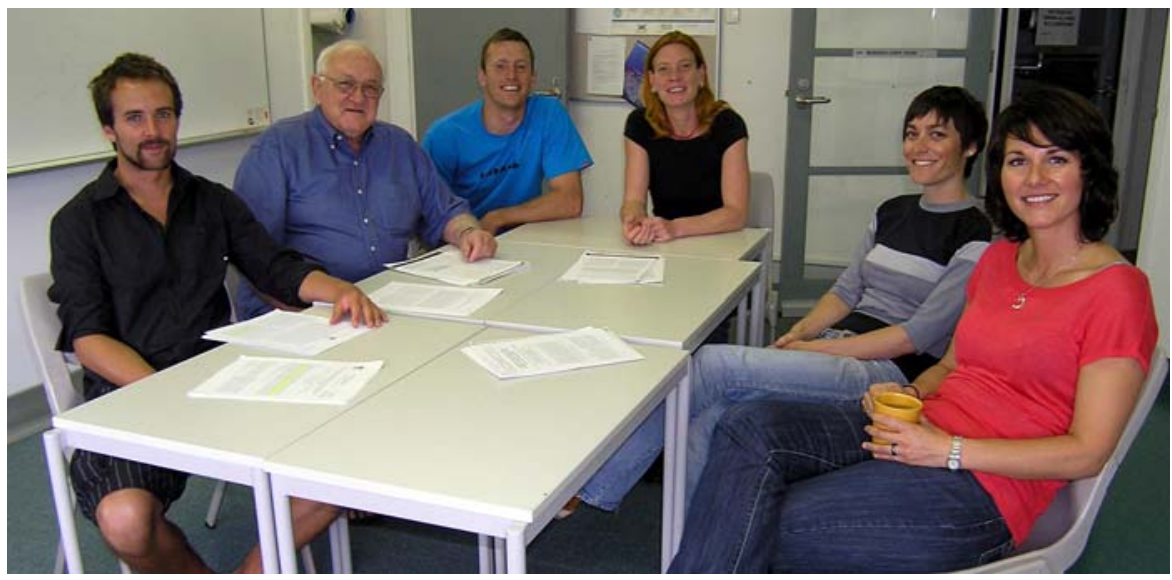

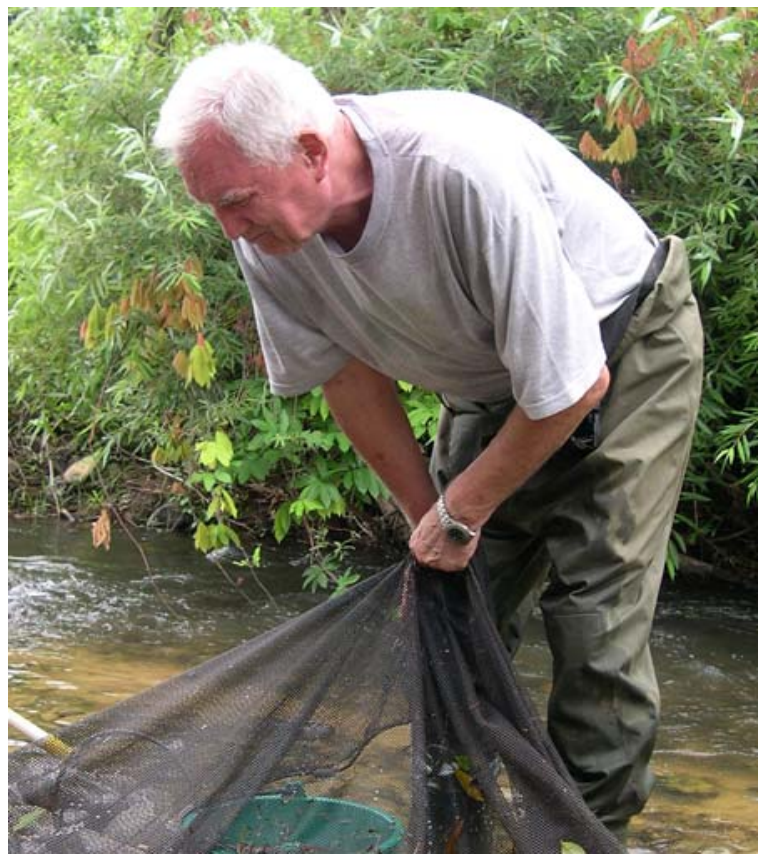

Fig. 2 Bill Beamish, now a Professor of Biology at Burapha University, investigating the environmental biology of freshwater fishes in Thailand (photograph courtesy of David L. G. Noakes)

(Potter and Hyndes 1999; Potter and Gill 2003) (Fig. 1). Bill left Canada after a distinguished career and moved to a professorship at Burapha University in Thailand (Fig. 2), where he too continues to pursue his teaching and research on fishes (Beamish et al. 2006). David Noakes has provided a detailed consideration of the origin and development of Environmental Biology of Fishes in a separate Editorial (Noakes 2009).

\section{References}

Beamish FWH (1979) Migration and spawning energetics of the anadromous sea lamprey, Petromyzon marinus. Environ Biol Fish 4:3-7

Beamish FWH, Potter I (1975) The biology of the anadromous sea lamprey (Petromyzon marinus) in New Brunswick. J Zool 177:57-72

Beamish FWH, Sa-ardrit P, Tongnunui S (2006) Habitat characteristics of the cyprinidae in small rivers in Thailand. Environ Biol Fish 76:237-253

Noakes DLG (2009) On the origins. Environ Biol Fish 86:000000

Potter IC, Gill HS (2003) Adaptive radiation of lampreys. J Gt Lakes Res 29(suppl):95-112

Potter IC, Hyndes GA (1999) Characteristics of the ichthyofaunas of south-western Australian estuaries, including comparisons with holarctic estuaries and estuaries elsewhere in temperate Australia: a review. Aust J Ecol 24:395-421

Potter IC, Prince PA, Croxall JP (1979) Data on the adult marine and migratory phases in the life cycle of the southern hemisphere lamprey, Geotria australis Gray. Environ Biol Fish 4:65-69 